\title{
IMÁGENES DE LA LITERATURA EN LA ESCRITURA ENSAYÍSTICA DE ABRAHAM VALDELOMAR
}

\author{
Javier Morales Mena* \\ Universidad Nacional Mayor de San Marcos
}

Resumen: El presente artículo estudia la escritura ensayística de Abraham Valdelomar. Se propone explicar cómo figura la literatura en los comentarios que realiza Valdelomar a propósito de ciertos autores de la literatura universal, hispanoamericana y peruana. Sostenemos que cuando escribe sobre el artista(dramaturgo/poeta), enfatiza su genialidad y su naturaleza profética como rasgos que definen su autenticidad; mientras que al abordar el arte(tragedia/poesía), encuentra en la orientación performativa el vínculo entre arte y sociedad. Siempre enlazadas, con ambas ideas sobre el artista y el arte, la escritura ensayística transmite una imagen de la literatura. Lo literario como aquel discurso que comporta un modelo conceptual y afectivo de mundo, un discurso cuya modelización afecta el sistema perceptivo en tanto que representa el mundo.

Palabras clave: Valdelomar, literatura peruana, tragedia, poesía, dramaturgia, arte.

* Javier Morales Mena es profesor de Literatura de la Universidad Nacional Mayor de San Marcos y de la Universidad Peruana de Ciencias Aplicadas. Ha publicado La trama teórica. Ensayos de teoría literaria y literatura comparada (Lima, UNMSM, 2010). Es miembro de la Asociación Peruana de Literatura Comparada (ASPLIC), afiliada a la Asociación Internacional de Literatura Comparada (ICLA). Estudió el pregrado y posgrado en Literatura en la Universidad Nacional Mayor de San Marcos. 
JAVIER MORALES MENA

Aвstract: The present article studies Abraham Valdelomar's essayistic writing. It is devoted to explain how Abraham Valdelomar figures out literature in the comments he makes on some universal, Hispano-American and Peruvian literature writers. We sustain that when Valdelomar writes about the dramatist or poet himself he emphasizes the writer's genius and prophetic nature as features that give account of his authenticity. But when he deals with the masterpiece itself (drama/poetry), he finds a link between art and society in the performative orientation. With these links, both the ideas about the writer and his literary work, the essayistic writing transmits a literary image. The literary issue as the discourse that contains a conceptual and affective world model, a discourse whose modeling affects the perceptual system meanwhile it represents the world.

KeY words: Valdelomar, Peruvian literature, drama, poetry, art

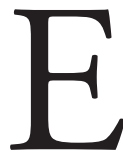

presente artículo se ocupa de uno de los géneros discursivos que frecuentó Abraham Valdelomar (1888-1919): el ensayo. Escritura cuya "naturaleza» porosa o esponjosa permite la combinación de diversos registros creativos y analíticos que lo definen como aquel escrito donde existe «un delicado compromiso entre el análisis y la intuición, entre el lenguaje expositivo y el metafórico, entre el conocimiento objetivo y la percepción íntima» (Oviedo 1991:12). Centramos nuestro interés en los ensayos que Valdelomar dedica a la «Literatura universal» («Shakespeare: Otelo, Hamlet, Romeo y Julieta»; y «Mauricio Maeterlinck y su arte»); la «Literatura hispanoamericana» («El duelo de las letras hispanoamericanas: José Enrique Rodó»; y «Dolores Sucre: duelo de las letras americanas»); y la «Literatura peruana» («Enrique Bustamante y Ballivián»; «Exégesis estética de Panoplia lírica»; «La rueda invisible de Luis de Góngora»; $\mathrm{y}$ «La génesis de un gran poeta: César A. Vallejo el poeta de la ternura»). ${ }^{1}$

1 El ordenamiento de los ensayos en estos tres segmentos categoriales: universal, 


\section{IMÁGENES DE LA LITERATURA \\ EN LA ESCRITURA ENSAYÍSTICA DE ABRAHAM VALDELOMAR}

Aunque los marcadores discursivos que componen los títulos refieran a obras y autores. Aquellos son escritos breves que no están compuestos con un lenguaje especializado. Lo que encontramos es el despliegue de reflexiones respecto del arte (tragedia y poesía) y el quehacer del artista. Se realiza un acercamiento biográfico y circunstancial al autor; se tematiza el contenido de las obras; y se corrige las opiniones de sentido común. Ciertamente son escritos que modelan la comprensión estética de un sujeto hermenéutico. Adelantamos: cada vez que Valdelomar comenta el origen del proceso de producción artística subraya que es la sensibilidad aprehensiva del artista lo que hace posible el arte. Si hacemos extensiva esta idea a la escritura ensayística, podemos entender que el sujeto hermenéutico es quien comprende e interpreta el mundo haciendo uso de su sensibilidad y sus emociones. No ha hipotecado ni amputado sus afectos, ni sentimientos, para buscar una lectura epistemológica de la realidad. El comentario y la declaración personal se traman. Una suerte de autocontemplación con la que el ensayista logra representarse en lo representado. Lo que se dice de otro como decir de sí mismo: «una cristalización parcial de sí mismo» (Earle 1982: 50).

De extensión variable, firmado algunas veces con nombre propio o con el seudónimo «El Conde de Lemos», los escritos de Valdelomar se publicaron en diarios como La Prensa, La Opinión Nacional, Colónida, Revista de actualidades, Sudamérica y La Crónica. ¿Artículos periodísticos, crónicas o ensayos? Como hipótesis de lectura asumimos que el corpus a explicar se enmarca dentro de la escritura ensayística. No precisamente por estar delimitado de otros géneros discursivos. Más bien porque la esponjosidad

hispanoamericano y peruano figura en VAldelomar, Abraham. Abraham Valdelomar. Obras completas. Tomo IV. Edición, prólogo, cronología, iconografía y notas de Ricardo Silva Santisteban. Lima: Ediciones COPÉ, 2000, pp. 169-301. En adelante todas las referencias provienen de dicha fuente. 
señalada líneas arriba determina que el ensayo se acerque al artículo periodístico y a la crónica, es más: «no solo muchos grandes ensayos tienen origen periodístico (los de José Carlos Mariátegui son un buen ejemplo) sino que fue el periodismo el que, a partir del siglo XVIII, estimuló el interés por el género y facilitó su difusión. Ambos comparten una finalidad principal: la divulgación, que contribuye al debate y movilidad de las ideas» (Oviedo 1991: 16, las cursivas son nuestras).

Son escasos los artículos que se ocupan de explicitar los hilos discursivos de la textualidad ensayística de Valdelomar. A lo sumo encontramos conjeturas o ideas dispersas que cuando se refieren al ensayo o la crónica subrayan la versatilidad de su escritura (Cornejo 1980: 88; Delgado 1980: 103). La lectura que realizamos formula una interrogante a esta escritura enmarcada dentro del abierto código del ensayo: ¿cómo figura la literatura en los comentarios que realiza Valdelomar a propósito de ciertos autores de la literatura universal, hispanoamericana y peruana? Sostenemos que cuando escribe sobre el artista (dramaturgo/poeta), enfatiza su genialidad y su naturaleza profética como rasgos que definen su autenticidad; mientras que al abordar el arte (tragedia/poesía), encuentra en la orientación performativa el vínculo entre arte y sociedad. Siempre enlazadas, con ambas ideas sobre el artista y el arte, la escritura ensayística transmite una imagen de la literatura. Lo literario como aquel discurso que comporta un modelo conceptual y afectivo de mundo, un discurso cuya modelización afecta el sistema perceptivo en tanto que representa el mundo.

1. «Literatura universal»: Valdelomar escribe comentarios sobre algunos autores que explicaremos a continuación. «Shakspeare: Otelo, Hamlet, Romeo y Julieta. Un tomo de la Biblioteca de la prensa». Atendamos la siguiente cita: 


\section{IMÁGENES DE LA LITERATURA \\ EN LA ESCRITURA ENSAYÍSTICA DE ABRAHAM VALDELOMAR}

Shakespeare mezcla la vida real con una porción imprecisable de Extraordinario. Envuelve a los hombres en espesas redes presionantes, y la voluntad humana sondea, ayuda, acompaña o vence al Destino. Su teatro es intenso en el desarrollo, filosófico en la frase, inquietante y profundo en la ideología, real en la vida y extraterrestre en su realismo. Hamlet, el joven inconexo y taciturno, es más que el príncipe danés vengador de un crimen impalpable, es el símbolo de la Perpetua Duda Trascendental. El Hamlet es genial porque en él, en su demacrada figura noble y tétrica, en su extraviada originalidad, en su tedio perseverante, en su austeridad juvenil, en su acendrado sentimentalismo, en su perpetua inquietud, en sus lamentaciones patéticas, en su acervo moral, en su delicadeza fuerte, en sus voliciones inexorables, es un momento simbólico de toda la especie humana. Es genial porque Hamlet es el hombre, son todos los hombres, es la vida y es toda la vida, es la Duda; es el Bien y el Mal, la eterna dualidad trágica; es la Naturaleza imperecedera y múltiple, pero vacilante y adolorida siempre. (173)

¿Qué es lo que se advierte en la extensa referencia? En primer lugar, el comentario a propósito de los materiales con los que Shakespeare compone sus dramas: lo cotidiano y lo extraordinario. Esto es: la historia que cuenta el drama toma los hechos que acontecen al hombre de carne y hueso, ya sea para mundanizarlo o para resaltar su trascendentalidad. En segundo lugar, el comentario subraya la vitalidad y dinamismo que le da la intensidad del ritmo al desarrollo de las acciones; esta observación se complementa a otro nivel con la caracterización de la dicción shakesperiana: la escritura es filosófica y la comunicación del contenido, profundo e inquietante: «su teatro es intenso en el desarrollo, filosófico en la frase, inquietante y 
profundo en la ideología, real en la vida y extraterrestre en su realismo». Y en tercer lugar, deja de lado el comentario general para centrar la atención en Hamlet. No le interesa explicar qué acciones realiza, tampoco detallar qué funciones cumple; lo fundamental es dejar claro que el personaje representa al ser humano, Hamlet es símbolo del hombre: «Hamlet es el hombre, son todos los hombres, es la vida y es toda la vida, es la Duda; es el Bien y el Mal, la eterna dualidad trágica; es la Naturaleza imperecedera y múltiple, pero vacilante y adolorida siempre».

La tragedia figura como un modo de comprender la realidad; un modo simbólico de entender el curso de los hechos. El comentario se despliega como la escritura que establece el contacto entre el mundo y el texto dramático. No solo como el discurso especializado que describe los componentes formales, sino más como discurso que persigue establecer contactos entre el texto y el mundo; el discurso y lo humano. Es como si el comentario mundanizara el relato o la historia dramática. La identificación simbólica, subraya la condición paradigmática que tiene la tragedia — se habrá notado que se escribe de Shakespeare y de Hamlet no para pensar en nacionalismos literarios-. Con todo ello, el género literario resulta un modo de conocimiento del hombre; un método de exploración de lo humano, lo demasiado humano. El drama como una exploración de la psicología humana. ¿Comentario filosófico o literario? Lo cierto es que uno de los tópicos del ensayo modernista indica que «el Modernismo reanimó la antigua lucha entre arte y filosofía — favoreciendo, claro, al primerotambién profesaba una conciliación» (Earle 1982: 55). La conciliación se define en este caso en la percepción filosófica de la tragedia.

«Mauricio Maeterlinck y su arte». La premisa de la que parte Valdelomar en este comentario periodístico tiene que ver con el arte: «los elementos esenciales para que se produzca una obra artística: el hombre y la 
naturaleza. El arte es la naturaleza vista a través de un espíritu especial [...] una obra de arte será más grande cuando el artista sea más sensible, cuando su espíritu sienta más a la Naturaleza» (174). ¿Qué es lo que se percibe? Una especie de poética que concibe al artista como el ser dotado de una sensibilidad superior que le permite comprender y aprehender el espíritu de las cosas: "para los principales modernistas, arte y poesía eran revelación más que creación. Y lo que había que revelar era la magnitud y la belleza del universo» (Earle 1982: 52). Este procedimiento sensible y cognoscitivo caracteriza al escritor y a su quehacer artístico. Al comentar algunas tragedias diferencia la sensibilidad que las construye y las dimana:

Prometeo lamentándose ante las oceánidas, nos hace el efecto de un coloso, pero no llega en dolor a pasar nuestro espíritu. Sus palabras muy bellas y nobles no nos dicen nada más allá de ellas mismas. Habría que dar un salto desde Shakespeare, hasta Maeterlinck y D’Annunzio, hasta Maeterlinck sobre todo, para reconocer un arte nuevo en literatura, una senda misteriosa que se abre ante nuestro espíritu, que nos dice algo que no está en las palabras [...] Esquilo causa respeto. Dante da miedo. Shakespeare da ideas. Maeterlinck da pavor. Es misterioso y grande, profundo y sutil, es la naturaleza misma puesta en palabras. (176, las cursivas son nuestras)

La sensibilidad aprehensiva de cada uno de los autores difiere. Ello supone que algunos se encuentran más distanciados de la naturaleza y otros más cerca a ella. Pero lo importante quizá no radica en quién está más cerca o más lejos, sino más bien en el hecho que motivan: «Esquilo causa respeto. Dante da miedo. Shakespeare da ideas. Maeterlinck da pavor». ¿Calificativos para dejar de lado? ¿Atribuciones superficiales? No. Las concisas palabras 
tienen una extensión mayor. Marcan la pauta de las reacciones que produce el discurso literario. Son enunciados que denotan la acción performativa de la literatura. El comentario de Valdelomar señala no solo el genio del artista moderno como el más capacitado para representar el mundo, sino también la naturaleza de la literatura como aquel discurso que tiene un impacto performativo.

2. "Literatura hispanoamericana»: los escritos de este grupo son despedidas fúnebres a autores representativos que dejaron de existir. Comentarios o notas breves de duelo. En ellos incorpora ideas concernientes al arte y la ética. Se conecta con las anteriores acotaciones a propósito de la «Literatura universal» en tanto el discurso literario está muy vinculado a los avatares de la vida cotidiana. ¿Pacto de referencialidad? ¿Exigencia de representación realista? El gozne entre literatura y vida va más allá de un contrato de representación o hipoteca de referencialidad. Hunde sus raíces en motivaciones más profundas. Lo literario es un discurso que permite comprender los dramas y sueños del ser humano. El discurso literario es la morada del ser; del ser que celebra y padece la vida. La mirada de Valdelomar a propósito de la literatura resulta importante porque permite comprender que esta no es ningún terreno neutral. La trama de su prosa, el entretejido de su fibra narrativa tiene la motivación de revelar o comprender lo humano. Las insistentes palabras en torno al arte como ética y cómo religión, o como símbolo y paradigma, buscan modelar una idea de arte vinculado a la existencia. Prestemos atención, por ejemplo, el obituario titulado «El duelo de las letras hispanoamericanas: José Enrique Rodó»: «Allí, bajo el cielo, cúpula inmensa del italiano templo, se ha apagado para siempre una de las vidas más ilustres de América [José Enrique Rodó], uno de esos hombres — cada día más raros - en quienes el arte es una religión y una moral» (190). Dicción de duelo. Escritura que honra o tributa la memoria de 


\section{IMÁGENES DE LA LITERATURA \\ EN LA ESCRITURA ENSAYÍSTICA DE ABRAHAM VALDELOMAR}

vida del influyente autor de Ariel (1900). Pero también palabras que presentan de modo simplificado dos ideas respecto al modo de comprender y practicar el arte: como religión y como moral. Esto es, el arte como una práctica sagrada de creencia y de fe; y el arte como pauta de comportamiento que orienta la vida. Dentro del mismo tenor, «Dolores Sucre: duelo de las letras americanas» despide a la poeta ecuatoriana y celebra su modo de comprender la poesía: «sus versos fueron el catecismo sentimental donde sus compatriotas primero y los americanos todos después, tuvieron las primeras emociones que produce esta fatiga dolorosa del vivir [...] consagramos un recuerdo a la mujer espiritual y romántica que cantó al amor, el dolor y a la vida precaria y triste» (193). Dos insistencias. La primera correspondiente a la visión trágica de la vida o la existencia. La segunda orientada a reafirmar el gozne entre discurso literario y vida. No es casual. Una de las motivaciones características de los ensayistas modernistas era exigir que el arte intervenga y participe estratégicamente en todo aquello que afecte a la sociedad y la cultura (Cf. Earle 1982:52).

3. «Literatura peruana»: de este marco territorial hemos elegido los que consideramos más representativos: «Enrique Bustamante y Ballivián», «Exégesis estética de Panoplia lírica», «La rueda invisible de Luis de Góngora» $\mathrm{y}$ «La génesis de un gran poeta: César A. Vallejo el poeta de la ternura». Cuando Valdelomar escribe sobre «Enrique Bustamante y Ballivián» señala que su originalidad radica en haberse liberado de las viejas formas de hacer poesía: «¿Cuántas vulgaridades nos han dicho espíritus selectos, por no haber roto a voluntad la cadencia de una armonía convencional y escolástica?» (224). La pregunta retórica es contestación que descarta del plano artístico el imperativo de lo convencional (normas/reglas). Valdelomar calibra la actualidad del poeta según dos ideas complementarias: ruptura y novedad. La primera vendría ser el acontecimiento que marca el abandono o cancelación de lo previsible, de 
lo convencional. Por lo mismo, la segunda, sería el grado cero desde donde lo novedoso se potenciaría y desplegaría. Tradición de la ruptura. Ruptura de la tradición. La implícita valoración temporal es importante por cuanto cada expresión artística sería el resultado de la necesidad «simbólica» que tiene una época. Simplificado el razonamiento: «la vida moderna, completamente distinta de la precedente, no puede valerse de los mismos medios expresivos» (224). Lo moderno como acontecimiento de ruptura, es advenimiento de la diferencia expresiva; el despliegue de lo irrepetible. «Es necesario, pues, crear un nuevo arte, tan sincero como el antiguo, pero más en armonía con el sentir moderno. Expresar espontáneamente las ideas, libertarse del prejuicio académico y el yugo clásico; ser libres, veloces y concisos [...] Bustamante es el primero de los poetas peruanos que da el hachazo en la selva y penetra en el mundo de los nuevos principios» (225).

Al prestar atención al poeta arequipeño Alberto Hidalgo «Exégesis estética de Panoplia lírica», Valdelomar presenta algunas ideas respecto a la poesía y el poeta. Reflexiones que se integran dentro del marco de ideas respecto al arte. Cito extensamente:

La función del artista, en este caso del poeta, es descubrir por el sentimiento lo que la naturaleza tiene de eterno y esquivo. El poeta es un cazador de infinito; un buceador de verdad en el abismo del misterio; un vidente que descubre la belleza en las mudas nebulosas de lo objetivo. El verso es el punto del espacio donde se cruzan el espíritu exaltado del artista y el instante revelado del cosmos. La verdadera obra inmortal en el poeta es aquella conjunción de su alma con el alma de la naturaleza. El espíritu engendrado a la sustancia cósmica es la obra de arte. Cuando un punto del éter se fija por las coordenadas máximas 


\section{IMÁGENES DE LA LITERATURA \\ EN LA ESCRITURA ENSAYÍSTICA DE ABRAHAM VALDELOMAR}

del alma humana, del tiempo y de la naturaleza, se produce la obra inmortal. Es, pues, menester, buscar en la obra del poeta estas raras conjunciones. (241)

Explicativo, esotérico y místico; la dicción de Valdelomar presenta en esta referencia algunos elementos que acompañan su reflexión respecto al arte en general, y la literatura en particular —entiéndase aquí poesía—. Figuran en aquella los roles que cumple el poeta y la poesía. Representado como «cazador» $\mathrm{y}$ «buceador», el poeta tiene la función de indagar por lo inaprehensible, la belleza y la verdad. Titánico reto para el que cuenta con «el sentimiento», esto es, la sensibilidad como catalizador del conocimiento. ¿Crítica a la razón pura? ¿Epistemología poética? ¿Negativa a amputar la sensibilidad o los sentimientos de toda teoría del conocimiento? Lo cierto es que con estos sabios propósitos el poeta se modela como el más capacitado para revelar el misterio del mundo. ¿Guardián de la belleza? ¿Pastor de la verdad? Su función está más cerca a la de un profeta que tiene el símbolo, la imagen o la palabra del por-venir: «los ensayistas de entonces, en sus mejores momentos, poetas, se sentían profetas» (Earle 1982:54). La poesía, por otra parte, es el resultado de este proceso de intelección sensible y revelación mística. Como espacio de encuentro y revelación de espiritualidad humana y la trascendentalidad cósmica, la poesía, es «obra inmortal». Recordemos que las líneas glosadas atañen a la poesía de Hidalgo. Por ello, atiéndase las siguientes palabras: «confesemos que Hidalgo posee una técnica que muy pocos tienen al fin del camino de la vida. No sólo es la pulcritud de la forma, la concisión del pensamiento, la riqueza abundante de metáforas, el giro nuevo y gentil sino la claridad y el sabio método en la exposición de las ideas» (246). Poeta-poesía-poema. Como se habrá notado, la idea de poesía se amplía y complementa en la materialización. No todo queda en lo metafísico y trascendental; en términos de composición, el 
poema no solo es superficial, es una estructura compleja que demanda diseño, arquitectura, conocimiento técnico.

«La rueda invisible de Luis de Góngora» es otro comentario, que aunque no pertenezca a la tradición peruana, es incluida dentro de ella sin precisar el por qué. En esta nota sobre el poeta español Luis de Góngora, Valdelomar realiza una distinción entre lo trágico y lo dramático:

La rueda invisible es una obra donde se realiza la maravilla de un autor que concibe la tragedia tal como la tragedia debe ser, pero en cuyo espíritu moderno y versátil no anida la tragedia. Si Góngora fuera un torturado, un inquieto, un preguntador, un sondeador de lo misterioso y lo siniestro, si su espíritu estuviera acostumbrado a ulular en las sombras el rastro de la muerte, si su alma fuera un nido de las trágicas aves agoreras de los presentimientos, nos habría ofrecido una obra con menos sentido de la carne, con menos calor de pasión, con menos angustias orgánicas [...] por ello la obra del joven triunfador no es una tragedia. Es un drama [...] el autor ha querido ofrecernos una obra cuyo sentido dramático estuviera al alcance del instinto, mas no de la inteligencia de su público. (260)

Fármaco que alivia las dolencias de la sociedad a través de la catarsis. Vinculada a los desenlaces funestos que causan conmiseración. Lección filosófica de la vida: la tragedia tendría el signo de obra inmortal por cuanto representa el sentido trágico de la existencia, «si su espíritu estuviera acostumbrado a ulular en las sombras el rastro de la muerte», "nos habría ofrecido una obra con menos sentido de la carne». Lo que está en discusión es que el autor de La rueda invisible — si bien ha compuesto una pieza teatral que cumple con todos los requisitos formales que le hacen gozar de aceptación- 
no ha logrado crear una obra inmortal, debiéramos decir, existencial. A lo más — va la distinción — una pieza dramática donde el imperio de las pasiones deleita, entretiene, adormece los sentidos; pero no conmueve la razón y no aguza la inteligencia. También encuentra una contradicción de orden entre la actitud del creador y la creación. Una falta de sincronía entre la forma de expresión y la sustancia de expresión; la composición es como debe ser; no obstante, carece de una visión del sentido de la vida: «La rueda invisible es una obra donde se realiza la maravilla de un autor que concibe la tragedia tal como la tragedia debe ser, pero en cuyo espíritu moderno y versátil no anida la tragedia». En parágrafos anteriores expusimos que uno de los requisitos que Valdelomar exigía para que la obra artística alcance la inmortalidad era que debía lograr articular, en la materialidad expresiva, el ser y el tiempo: «es necesario, pues, crear un nuevo arte, tan sincero como el antiguo, pero más en armonía con el sentir moderno» (225). No encuentra que la obra de Góngora cumpla esta exigencia. Se desprende del juicio que el sistema de valores que organiza su poética está signado por el sentido trágico de la vida. Por el temor y el temblor del ser echado al mundo.

Valdelomar aborda a Vallejo en «La génesis de un gran poeta: César A. Vallejo el poeta de la ternura», aunque no desarrolla ideas sobre Los heraldos negros; le dedica algunas palabras al autor:

Hay en tu espíritu la chispa divina de los elegidos. Eres un gran artista, un hombre sincero y bueno, un niño lleno de dolor, de tristeza, de inquietud, de sombra, y de esperanza. Tú podrás sufrir todos los dolores del mundo, herirán tus carnes los caninos de la envidia, te asaltarán los dardos de la incomprensión; verás quizás, desvanecerse tus sueños, podrán los hombres no creer en ti; serán capaces de no arrodillarse a tu paso los esclavos; pero, 
sin embargo, tu espíritu, donde anida la chispa de Dios, será inmortal, fecundará otras almas y vivirá radiante en la gloria, por los siglos de los siglos. Amén. (264, las cursivas son nuestras)

Oración que celebra la condición trascendental del artista. La semántica que lo define remarca su «dolor», «tristeza» $\mathrm{y}$ «sufrimiento». ¿Un pequeño dios que resiste el embate de los apóstatas? No resulta raro. Baste recordar que en el tratamiento de la figura del poeta, Valdelomar insiste frecuentemente en la imagen del genio —el iluminado, el aurático-. E incluso en la imagen del artista como profeta que revela el misterio del mundo. Mediante aquellas palabras que presentan la espiritualidad de Vallejo, percibimos además, la advertencia del horizonte de recepción. La nueva sensibilidad puede causar rechazo. La novedad puede provocar hostilidad. El poeta o profeta debe estar preparado. ¿Máximas estéticas para una poética de resistencia?

4. Coda: habíamos planteado la pregunta ¿cómo figura la literatura en los comentarios que realiza Valdelomar a propósito de ciertos autores de la literatura universal, hispanoamericana y peruana? Nuestra lectura ha hecho evidente que el discurso literario tiene una orientación performativa que define su participación e implicancia en la esfera social. Es decir, aquello que era motivación de los ensayistas del Modernismo - la exigencia a intervenir en todo aquello que afecte a la sociedad y la cultura (Cf. Earle 1982: 52) _ es resultado del cumplimiento de un imperativo: representar los avatares de la existencia humana. Representación que — hemos visto - no consiste en una hipoteca referencial; sí en cambio, en comprender la importancia de sincronizar la existencia del ser con las circunstancias de su tiempo. En palabras de Valdelomar: «la vida moderna, completamente distinta de la 
precedente, no puede valerse de los mismos medios expresivos. Es necesario, pues, crear un nuevo arte, tan sincero como el antiguo, pero más en armonía con el sentir moderno». Los géneros que Valdelomar prefiere comentar son la tragedia y la poesía. Percibe en la primera una forma de conocimiento. Conectada directamente con el mundo, por colocar en escena al hombre en situaciones extremas que le demandan deliberaciones. La tragedia contendría el saber más trascendental para el hombre. La segunda es revelación profética de la belleza y la verdad. Ambas son resultado de un proceso de intelección que tiene como motor la sensibilidad y los afectos. 


\section{BIBLIOGRAFÍA}

a) Bibliografía primaria

VAldelomar, Abraham

2000 Abraham Valdelomar. Obras completas. Tomo IV. Edición, prólogo, cronología, iconografía y notas de Ricardo Silva Santisteban. Lima: Ediciones COPÉ.

b) Bibliografía complementaria

Cornejo Polar, Antonio

1980 «Historia de la literatura del Perú republicano». En Fernando Silva Santisteban (ed.). Historia del Perú. T. VIII. Lima: Mejía Baca, pp. 9-188.

Delgado, Washington

1980 Historia de la literatura republicana. Lima: Rikchay Perú.

EArle G., Peter

1982 «El ensayo hispanoamericano, del modernismo a la modernidad». Revista Iberoamericana, N. ${ }^{\text {os }}$ 118-119, Vol. XLVIII. Enero-junio, pp.47-57.

Oviedo, José Miguel

1991 Breve historia del ensayo hispanoamericano. Madrid: Alianza.

WEINBERG, Liliana

2007 Pensar el ensayo. México: Siglo XXI. 